\title{
Influence of Word Clouds on Critical Thinking in Online Discussions: A Content Analysis
}

\begin{abstract}
Beatriz M. Reyes-Foster ${ }^{1}$ and Aimee deNoyelles ${ }^{2}$
Abstract: This article presents an exploratory research study about the influence of word clouds on critical thinking when they are incorporated into online discussions. In an online discussion, students were asked to critically analyze two speeches, being assigned to one of two conditions: one in which the text was linear, and one in which the text was presented in the form of word clouds. Discussions posts were coded in two blended sections of an undergraduate anthropology course to assess the type and frequency of critical thinking demonstrated therein. Students in the word cloud condition exhibited more instances of critical thinking than students in the linear condition, and more often paired articulation of thought with the citing of evidence. The article concludes with recommendations for other educators interested in implementing a similar approach.
\end{abstract}

Keywords: online discussions; word clouds; critical thinking; content analysis; online learning and teaching; undergraduate education

\section{Introduction}

Online and blended course enrollments continue to rise in higher education institutions in the United States. While the overall student population has grown at an annual rate of $2.5 \%$ from $2002-$ 2012, students taking at least one online course grew 16.1\% to reach an all-time high of 33.5\% (Allen \& Seaman, 2014). With the increased popularity of online instruction, it is concerning that in such environments it can be challenging to support student development of critical thinking skills, which is an overarching goal in higher education (Behar-Horenstein \& Niu, 2011). While there are many definitions for critical thinking, for purposes of this article, it is defined as the ability to purposefully reflect and articulate one's own thinking while engaging in tasks that require evaluation, analysis, and application of previous knowledge. Learners with critical thinking skills have the ability to analyze and evaluate information, make reasoned judgments, consider alternatives, think open-mindedly, reflect on the thinking process, and communicate effectively (Beyer, 1987; Facione, 1990; Simpson \& Courtney, 2002). Lai (2011) recommends that educators use ill-structured problems that involve authentic contexts and support multiple perspectives to stimulate critical thinking. Effective assessments of critical thinking require that students make their reasoning visible, with the measure being the quality of the response rather than "right" or "wrong" answers. Communication and collaboration with peers are essential elements, as they allow multiple viewpoints to be shared and negotiated.

While previous research has found that students in online courses express a stronger preference to seek opportunities to use their critical thinking skills more than students in face-to-

\footnotetext{
${ }^{1}$ Department of Anthropology, University of Central Florida, 4000 Central Florida Blvd, Orlando FL 32816, beatriz.reyes-foster@ucf.edu.

${ }^{2}$ Center for Distributed Learning, University of Central Florida, 4000 Central Florida Blvd, Orlando FL 32816.
} 
face courses (Stedman \& Adams, 2014), it can be difficult to "provide opportunities, structures and formats that increase meaningful interaction and give students opportunities to practice and demonstrate critical thinking skills” (Joyner, 2012, p. 35) in the undergraduate online environment. For this reason, it is important to identify tools and strategies that support online learners to develop and exhibit critical thinking skills. One very popular tool used in online courses is the asynchronous discussion, in which students communicate mainly through text (although audio and video are sometimes supported) by posting messages, typically in response to a provided discussion prompt which asks them to think about the course material. Discussion prompts can range from simple question-and-answer, to open-ended, to highly structured. In a survey of instructors, Lynch, Kearsley, and Thompson (2011) found that 88\% of participants believed or somewhat believed that online asynchronous discussions positively impacted student learning.

Word clouds, which are visual representations of a document's text (Kaptein, Hiemstra, \& Kamps, 2010), emerge as a tool to potentially further support critical thinking within the context of online discussions. A word cloud takes the most frequently used words in a particular text and randomly displays them by size, based on their frequencies (DaPaolo \& Wilkinson, 2014). Word clouds show promise to encourage critical thinking in online discussions because more critical thinking occurs when students are active in thinking about the content (Paul \& Elder, 2000). DaPaolo and Wilkinson (2014) offer several ways they could be used to assess learning, such as providing a graphical representation of student learning, analyzing papers or writing, and comparing responses. Hayes (2008) emphasizes that word clouds aid students' reading and writing skills by requiring that students make connections between the large and smaller words. They can help a student understand major themes, identify unfamiliar terms, review previous materials, theorize connections among words, and encourage students to read the full text (Bandeen \& Sawin, 2012; Bromley, 2013; Edyburn, 2010). Ramsden and Bate (2008) propose issues to consider when implementing word clouds, such as paying careful attention to the ways the words appear in the cloud and removing words that are misleading or unnecessary. They also caution that word clouds do not always portray the context of the words accurately.

Online discussions provide a forum for students to make their reasoning visible, and communicate and collaborate about ill-structured problems that enable multiple viewpoints. In this exploratory study, we examine how critical thinking is influenced and exhibited when word clouds are incorporated into an online discussion. We compare results with an online discussion which does not feature word clouds.

\section{Literature Review}

While online discussions have the potential to support the development of critical thinking skills, mixed findings exist in the literature. Online discussions rarely exhibit the highest levels of cognitive presence such as connecting ideas and viewpoints, and applying ideas to other contexts (Celentin, 2007; Darabi, Arrastia, Nelson, Cornille, \& Liang, 2011; Garrison, 2007). There are several factors to explain this. The structure of the discussion board has been found to be an influence. For instance, Tu, Blocher and Gallagher (2010) explored threaded versus unthreaded discussions and found that while threaded discussions helped students reply to postings more easily, unthreaded discussions helped synthesize students' ideas in a more linear manner. Past research suggests (see Darabi et al., 2011; Kanuka, Rourke, \& Laflamme, 2007, Nussbaum, Winsor, Aqui, \& Poliquin, 2007) that discussion prompts which require students to form arguments and solve complex problems encourage a higher level of critical thinking than basic 
question-and-answer formats. While students may prefer open-ended prompts, prompts such as debate and case-based scenarios generally exhibit higher levels of critical thinking (Richardson \& Ice, 2010). Facilitation techniques are also an influence. Questioning (Darabi et al., 2011; Yang, Newby, \& Bill, 2005) and challenging (Gerber, Scott, Clements, \& Sarama, 2005) are two techniques identified in past literature as being supportive of critical thinking. Arend (2009) found that less frequent but purposeful facilitation, such as asking neutral probing questions, is associated with more instances of critical thinking in online discussions.

There is growing anecdotal evidence concerning the effectiveness of word clouds in learning environments. Past articles have described strategies such as reviewing word clouds which encompass student notes on a subject (Huisman, Miller, \& Trinoskey, 2012), asking students to identify familiar and unfamiliar words related to an upcoming lesson (Nickell, 2012), and analyzing public speaking performances (Perry, 2012). However, there is little empirical research concerning the effectiveness of word clouds in learning environments. Baralt, Pennestri, and Selvandin (2011) asked students to create word clouds from their own writing and found that students generated more vocabulary and new grammatical tenses, and student comments exhibited engagement and peer interaction. They recommended that word clouds be used to promote reflection and brainstorming, as well as define main ideas. Student creation of word clouds has also been found as a strategy to manage a subject with extensive information, an important skill to exhibit in the workplace (Miley \& Read, 2012).

There is even less known concerning the incorporation of word clouds into online discussions. A notable exception is Joyner's (2012) study, which evaluated the use of word clouds in a discussion assignment to see if it stimulated deeper levels of critical thinking. Joyner found that converting students' posts into word clouds and having them reflect on the resulting visual elicited greater evidence of critical thinking. In a related study, Hamm (2011) examined students as they created word clouds that displayed their perception of course content and posted them in an online discussion. It was found that students engaged in critical reflection of their work and the work of classmates.

In a related article (deNoyelles \& Reyes-Foster, 2015), we found that when students interpreted text in the form of word clouds, they reported higher critical thinking scores on a survey than students interpreting the same text in the traditional linear fashion within online discussions. The goal of this paper is to extend that emerging finding by analyzing the content of the discussions themselves. While students interpreting text in word clouds within online discussions perceived higher critical thinking than students who did not, did the discussions actually exhibit it? Through this analysis, our growing knowledge extends past the after-the-fact self-report of the students.

\section{Methodology}

\section{Participants and Context}

Research was conducted in two class sections of an upper-division undergraduate anthropology course called Language and Culture at a large southeastern university in the United States. The course is a requirement for the anthropology major and fulfills requirements in several different programs as well as a diversity requirement, so the course attracts a large and diverse group of students. The course instructor (Reyes-Foster) was the same for both classes. Course enrollment in the Fall 2013 semester was 87, while 66 enrolled in the Fall 2014 semester. Both class sections were offered in blended format, meaning that class was held in person twice a week, with the rest 
of the coursework to be completed online. As part of the coursework, students participated in five online discussions, accounting for $40 \%$ of the final grade. The word cloud strategy was implemented in the fifth and final graded discussion of the two semesters.

\section{Data Collection and Procedure}

At the beginning of the semesters, students were randomly assigned into online discussion groups of 8-10 students each, which resulted in approximately 10-12 groups. These groups remained the same throughout the semester. For the final graded discussion, the groups were evenly randomly assigned into two conditions: word cloud and linear. For instance, in Fall 2013, Groups 1-6 were linear, while Groups 7-12 were word cloud. All students regardless of condition were provided with an identical discussion prompt (Appendix 1). This prompt, which asks students to read two speeches and guess the speakers, was designed to promote critical thinking. Because the topics covered in class focused on gender and race, a speech by Susan B. Anthony and a Civil-Rights era speech by John Lewis were selected for this discussion. The only difference between the two conditions was that students in the word cloud condition were presented with the speeches displayed in the form of word clouds (Figures 1, 2), while the students in the linear condition were presented with the speeches displayed in a typical linear fashion (Figure 3). For accessibility purposes, students in the word cloud condition were also provided with a list of words and frequencies they could download in case they were unable to view the word cloud images.

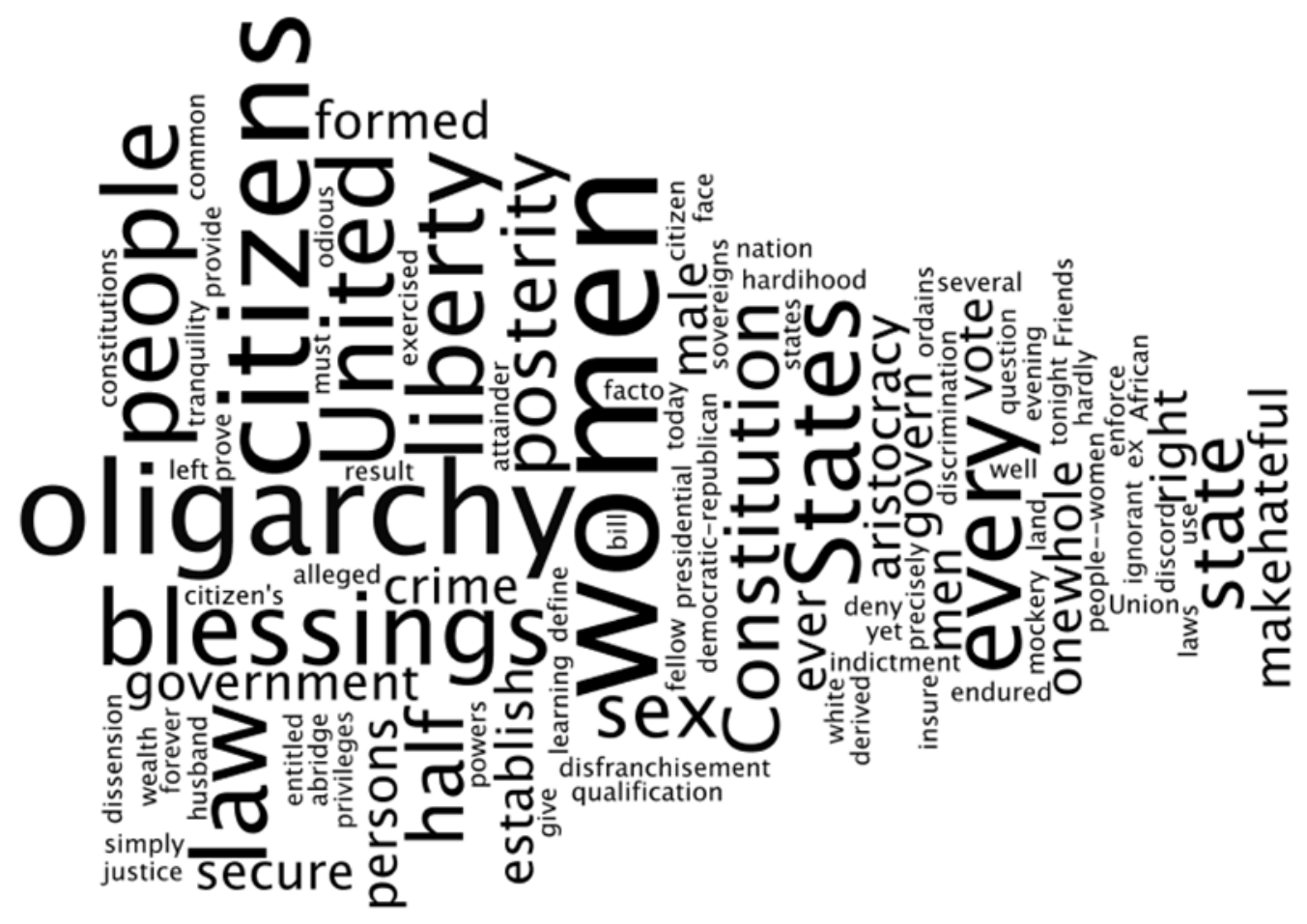

Figure 1. Speech \#1 in word cloud form. 


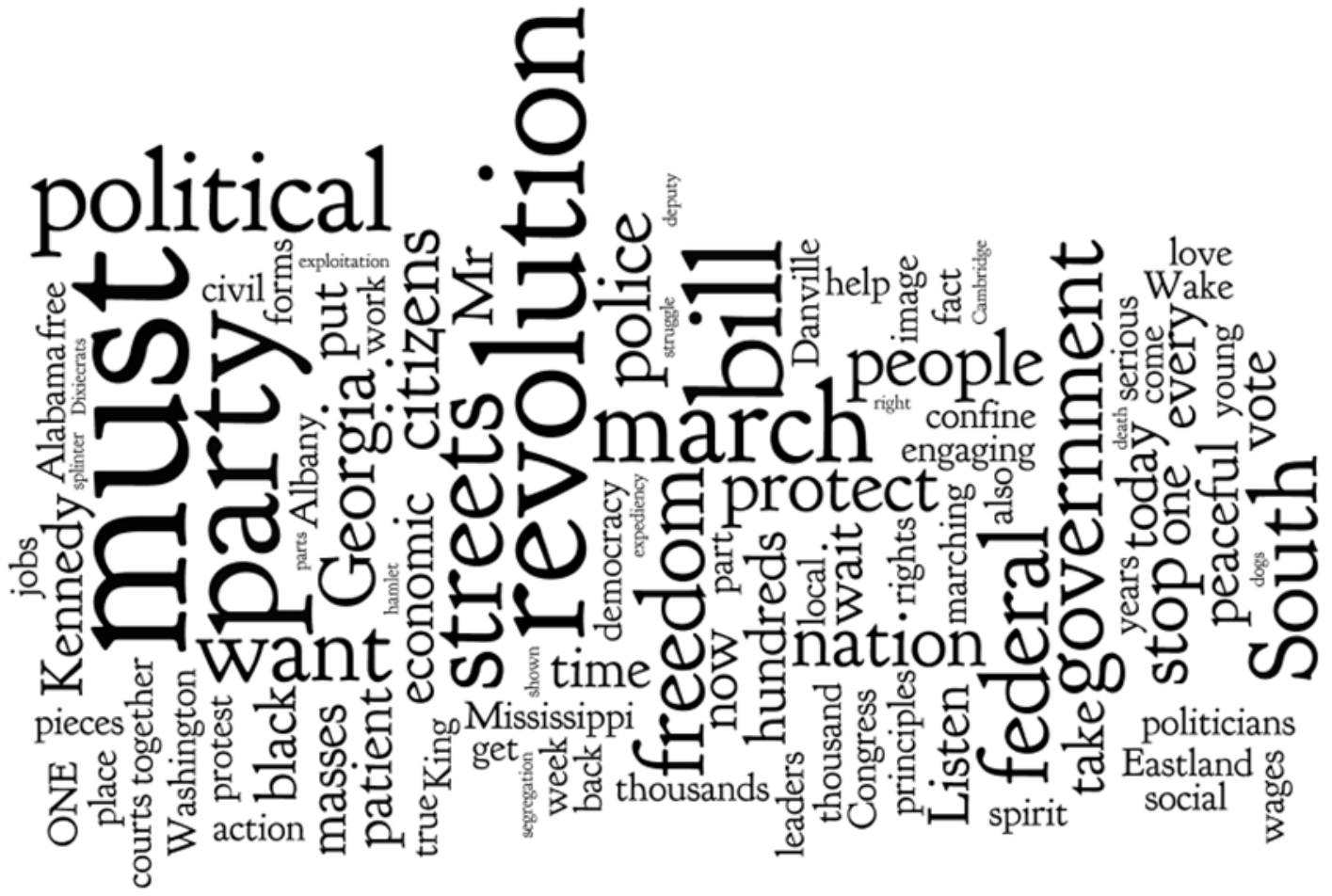

Figure 2. Speech \#2 in word cloud form.

Speech 1
Friends and fellow citizens, I stand before you tonight under indictment for the alleged crime of having voted at the last presidential election, without having a lauful
right to vote. It shall be my work this evening to prove to you that in thus voting, I not only committed no crime, but, instead, simply exercised my citizen's rights, guaranteed to
me and all United States citizens by the National Constitution, beyond the power of any state to deny.
The preamble of the Federal Constitution says:
"We, the people of the United States, in order to form a more perfect union, establish justice, insure domestic tranquility, provide for the common defense, promote the general
welfare, and secure the blessings of liberty to ourselves and our postenity, do ordain and establish this Constitution for the United States of America."
It was we, the people; not we, the white male citizens; nor yet we, the male citizens; but we, the whole people, who formed the Union. And we formed it, not to give the
blessings of liberty, but to secure them, not to the half of ourselves and the half of our posterity, but to the whole people-women as well as men. And it is a downight mockery
to talk to women of their enjoyment of the blessings of liberty while they are denied the use of the only means of securing them provided by this democratic-republican
govemment--the ballot.

Figure 3. Screenshot of excerpt of Speech \#1 in linear form.

After participating in the discussion, all students were required to complete a feedback survey (Appendix 2) in which they were asked to assess their own critical thinking and engagement vis à vis the discussion assignment (see deNoyelles \& Reyes-Foster, 2015, for results).

As per IRB approval, before the discussion commenced, the second author (deNoyelles) visited the classrooms and conducted Informed Consent protocols in the absence of Reyes-Foster, who was the instructor of record. Study information sheets were distributed and students were instructed to contact deNoyelles to opt-in to the study. Students who opted in received 3\% extra credit added to their grade as an incentive to participate, but were also presented with an alternative extra credit assignment in case they did not wish to participate. Students who did not opt in to the 
research study still were expected to complete the discussion for class, but were not included in the data analysis. 71\% of students in the Fall 2013 semester and 62\% of the Fall 2014 semester consented to participation in the study outlined in this article. We analyzed results only from the students who opted into the study. In addition, we downloaded participant discussion posts and replaced names with numbers to preserve confidentiality. In this article, we are concerned with the qualitative analysis of the discussion posts.

\section{Data Analysis}

While both critical thinking and engagement were explored, in this publication, we focus only on the analysis of critical thinking. We analyzed discussion posts using the Text Analysis Markup System (TAMS), an open-source qualitative analysis software designed for discourse research which aids in identifying themes in text. We used an iterative process to develop the critical thinking indicators to categorize the discussion data. To begin, we read several articles about the concept of critical thinking (Behar-Horenstein \& Niu, 2011; Facione, 1990) and explored coding processes previously employed by Yang et al. (2005), who studied critical thinking in online discussions. We created a preliminary coding template, and proposed codes such as identifying areas of disagreement, application, and justification. Then, each researcher independently coded one linear group and one word cloud group using the codes initially formed, but also developed new ones when applicable. Each 'complete thought' within a discussion post was coded, and it was possible to have several codes exist within the same sentence. We then reconvened to share and compare the emerging analysis in order to identify areas of disagreement, negotiate meaning, and agree on a preliminary list of codes. We independently coded two more groups (one word cloud and one linear), compared results, and further refined the list of codes to include only those which incorporated elements of critical thinking. The final list of codes, descriptions, and discussion examples related to critical thinking are presented in Table 1.

Table 1. Final codes.

\begin{tabular}{|l|l|l|}
\hline Code & Description & Discussion Example \\
\hline Relating prior knowledge & $\begin{array}{l}\text { Relate prior knowledge to } \\
\text { their guess }\end{array}$ & $\begin{array}{l}\text { "Tubman was known to be } \\
\text { involved with the church } \\
\text { during her women's rights } \\
\text { activism so it seems fitting.” }\end{array}$ \\
\hline Articulating thought process & $\begin{array}{l}\text { Articulating the sequence of } \\
\text { thought; making thinking } \\
\text { visible }\end{array}$ & $\begin{array}{l}\text { "When I looked at the } \\
\text { frequency list, other words } \\
\text { stood out to me such as bill, } \\
\text { discrimination, law, citizens, } \\
\text { United States, ballot." }\end{array}$ \\
\hline Citing evidence & $\begin{array}{l}\text { Makes a claim and provides } \\
\text { information to support it }\end{array}$ & $\begin{array}{l}\text { "The first speech is probably } \\
\text { written by a female. There } \\
\text { are several tips that would } \\
\text { make me believe this, such }\end{array}$ \\
\hline
\end{tabular}




\begin{tabular}{|c|c|c|}
\hline & & $\begin{array}{l}\text { as the issue of the right to } \\
\text { vote." }\end{array}$ \\
\hline Reflection & $\begin{array}{l}\text { Re-examining experience in } \\
\text { the light of other viewpoints; } \\
\text { integrating new knowledge } \\
\text { into one's conceptual } \\
\text { framework }\end{array}$ & $\begin{array}{l}\text { "Looking back at what I had } \\
\text { read, it really allows me to } \\
\text { consider these speeches to } \\
\text { be an example of language } \\
\text { as a display of verbal } \\
\text { artistry." }\end{array}$ \\
\hline Integration & $\begin{array}{l}\text { Forging } \begin{array}{c}\text { connections } \\
\text { between } \\
\text { speeches }\end{array} \\
\text { ideas and/or }\end{array}$ & $\begin{array}{l}\text { "The authors of each speech } \\
\text { were members of social } \\
\text { groups in different periods } \\
\text { of U.S. history that were } \\
\text { marginalized...the purposes } \\
\text { of these speeches was to } \\
\text { raise awareness of issues, to } \\
\text { educate fellow members and } \\
\text { address the perpetrators..." }\end{array}$ \\
\hline
\end{tabular}

We then coded together until we reached point of saturation at four groups, approximately $1 / 3$ of the posts. After this process, we separated all of the discussion posts into four sets divided by semester and prompt type (Fall 2013 word cloud, Fall 2013 word cloud, Fall 2014 linear, Fall 2014 word cloud). Because we had already reached saturation, we decided that it would be sufficient to code half of each group. Reyes-Foster coded half of the discussion posts from Fall 2014 (66 posts), and deNoyelles coded half of the discussion posts from Fall 2013 (68 posts). Because we had already conducted the initial coding together, we coded $20 \%$ of each other's sets (resulting in about 14 posts) in order to ensure inter-rater reliability in the coding procedure. We then ran an analysis using TAMS that compared each researcher's ratings, and found that we had $91 \%$ agreement. We found 12 codes in this group of $20 \%$ in which we disagreed. We discussed the discrepancies until we reached $100 \%$ consensus.

We conducted several descriptive analyses including the number of codes generated altogether, the number of particular codes, and the co-frequency of certain codes, in order to better understand the relationship between certain dimensions of critical thinking.

\section{Results}

In this section, we share results, including the total number of codes contained within the discussions, the frequency of codes related to critical thinking, and the co-frequency of particular codes related to critical thinking.

\section{Total Number of Codes}

For all of the discussion posts, a total of 708 critical thinking codes were generated. The majority occurred in the word cloud condition (Table 2). In total, there were 418 critical thinking 
codes in the word cloud condition and 290 critical thinking codes in the linear speech condition. This indicates that critical thinking was displayed more prominently for participants who received the speech in word cloud form.

\section{Particular Codes}

For all critical thinking categories but one, the word cloud condition outscored the linear (Table 2). The most dramatic result involved the code 'articulating thought process.' There were 90 more instances occurring in the word cloud condition than in the linear condition. The word cloud condition also outscored the linear in 'citing evidence' (16 more instances) and 'integration' (21 more instances). In addition, the word cloud condition had 24 more instances of 'reflection,' often occurring in the peer reply posts. The only code in which the linear condition outscored the word clouds was 'relating previous knowledge' (23 more instances). These are interesting results, given that the discussion prompt was identical for all students, regardless of the condition in which they were assigned.

Table 2. Frequency of critical thinking codes.

\begin{tabular}{|l|l|l|}
\hline Code & Word Cloud & Linear \\
\hline Articulating thought process & 145 & 55 \\
\hline Citing evidence & 135 & 119 \\
\hline Integration & 65 & 44 \\
\hline Reflection & 39 & 15 \\
\hline Relating previous knowledge & 34 & 57 \\
\hline
\end{tabular}

Beyond the larger frequency of critical thinking codes in the word cloud condition versus the linear speech condition, the overall content of the analysis contained within the discussion posts in each instance differed considerably from one another. Table 3 presents examples of what discussion posts looked like for each critical thinking code under both conditions. Examined in this way, the reader can see how having an entire linear speech available, as opposed to a word cloud which lacks context, results in somewhat different demonstrations of critical thinking. While participants in both conditions usually arrived at the same conclusion about the origins of the speeches, it was expressed differently depending on the condition. This was especially so with the codes 'articulating thought processes,' 'citing evidence,' 'relating prior knowledge,' and 'integration.'

Table 3. Critical thinking codes in word cloud vs. linear speech condition.

\begin{tabular}{|l|l|l|}
\hline Code & Word Cloud Condition & Linear Condition \\
\hline $\begin{array}{l}\text { Articulating thought } \\
\text { process }\end{array}$ & $\begin{array}{l}\text { I found the words “freedom", } \\
\text { "march”, and “revolution" and }\end{array}$ & $\begin{array}{l}\text { It is obvious that a Civil Rights } \\
\text { activist is speaking, because in the }\end{array}$ \\
\hline
\end{tabular}

Journal of Teaching and Learning with Technology, Vol. 5, No. 1, July 2016

jotlt.indiana.edu 


\begin{tabular}{|c|c|c|}
\hline & $\begin{array}{l}\text { immediately thought of the } \\
\text { civil rights movement. }\end{array}$ & $\begin{array}{l}\text { beginning he talks about the } \\
\text { inadequacy of “the administration's } \\
\text { civil rights bill. }\end{array}$ \\
\hline Citing evidence & $\begin{array}{l}\text { The key words in the cloud } \\
\text { that lead me to believe this are } \\
\text { "Kennedy," "peaceful,” } \\
\text { "south,” "revolution,” "king," } \\
\text { "Georgia,” "political," } \\
\text { "government," “politicians," } \\
\text { and “congress.” }\end{array}$ & $\begin{array}{l}\text { She states, "an oligarchy of race, } \\
\text { where the Saxon rules the African, } \\
\text { might be endured", and } \\
\text { subsequently, } \\
\text { discrimination against women... is } \\
\text { today null and void... as is every } \\
\text { one against Negroes." }\end{array}$ \\
\hline Integration & $\begin{array}{l}\text { [In the first wordle] the use of } \\
\text { the words "Makehateful", } \\
\text { "mockery" and "crime" give it } \\
\text { a much darker tone. The } \\
\text { second wordle speaks more of } \\
\text { "love", "peaceful", and } \\
\text { "protect" giving a sort of } \\
\text { hopeful message. }\end{array}$ & $\begin{array}{l}\text { While both speeches are aimed at } \\
\text { drawing attention to discrimination } \\
\text { and speaking out against certain } \\
\text { legal practices, Speech } 1 \text { is } \\
\text { overwhelmingly more docile than } \\
\text { Speech } 2 \text {. }\end{array}$ \\
\hline Reflection & $\begin{array}{l}\text { By examining the Wordle lists, } \\
\text { I already take more of a liking } \\
\text { to the second speech over the } \\
\text { first. Although I am unsure if } \\
\text { these connections are made in } \\
\text { the second speech, the } \\
\text { prevalence of key words } \\
\text { "“streets", "police”, "people", } \\
\text { "want”, "revolution") make } \\
\text { me feel particularly } \\
\text { reminiscent of current events } \\
\text { regarding police brutality, } \\
\text { ranging from the Wall Street } \\
\text { protest to the Ferguson } \\
\text { shooting of Michael Brown. }\end{array}$ & $\begin{array}{l}\text { I think this is a reason why my } \\
\text { interpretation of these speeches is } \\
\text { what it is. I knew they were } \\
\text { speeches and I knew how powerful } \\
\text { they were and how it affected } \\
\text { history so my interpretation became } \\
\text { skewed. }\end{array}$ \\
\hline $\begin{array}{l}\text { Relating } \quad \text { previous } \\
\text { knowledge }\end{array}$ & $\begin{array}{l}\text { The second speech has to do } \\
\text { with civil rights considering } \\
\text { the fact that Danville was a hot } \\
\text { bed of civil rights activity and } \\
\text { Mississippi was as well. }\end{array}$ & $\begin{array}{l}\text { I thought the speaker may have } \\
\text { been Susan B. Anthony or } \\
\text { Elizabeth Cady Stanton, since they } \\
\text { were both prominent female leaders } \\
\text { concerned primarily with ending } \\
\text { the disenfranchisement of women. }\end{array}$ \\
\hline
\end{tabular}

When those in the linear group 'articulated thought processes,' it tended to be expressed in a more sequential nature. For instance, "The third and fourth sentence lets you know the speaker 
is pissed off" exhibits a more linear reading and articulation of the text. The word cloud posts were more non-linear, stitching together randomly scattered words; "The first two words that hit me straight off were women and citizens, and as you continue reading through them, you see words like sex, inequality, disenfranchisement and qualification, all things a woman would be a lot more likely to experience than a man." The words in the cloud are not listed in any particular order, so the student is more pressed to articulate how he or she approached the analysis. The language in these posts is overall more instinctive. For example, the student in Table 3 describes seeing certain words and "immediately" thinking of the Civil Rights movement.

For the code 'citing evidence,' the linear group referenced phrases more than single words. For example, a student wrote, "The mention of 'women as well as men' was a dead giveaway that it was a women making this speech, which means it had to be around the late 1800's when all the women suffrage stuff was going on." Many more quotes from the speeches were used to back up points formed by participants in the linear group. In contrast, participants in the word cloud condition were forced to rely on words instead of phrases or quotes since there were no phrases or quotes contained within. One example from the discussion is, "Based on the words 'women' and 'sex' that are used frequently as well as specific notes of 'men' and 'male,' I am almost certain it is a female speaker." Only having single words prompted the student to closely examine the possible relationships between the words.

Students called upon their existing knowledge in different ways depending on whether they had the word cloud or the linear text. Without context, students in the word cloud condition generally associated their existing knowledge with specific words. For example, a number of them provided definitions for the word "oligarchy" in the first word cloud. Others flagged the presence of various place names in the second word cloud to identify it as a Civil Rights speech. For example, a student wrote, "I believe that the second speech has to do with civil rights considering the fact that Danville was a hot bed of civil rights activity and Mississippi was as well." In contrast, students in the linear condition frequently relied on their previous knowledge of both the Women's Suffrage and the Civil Rights movements to contextualize their writing, sometimes pulling large amounts of text from the prompt to support their opinions. One student wrote, "Referring directly to the protesting events of Americus, Georgia, the speech must have taken place during or after 1963, but before the Voting Rights Act of 1965." Thanks to the context clues present in the linear speech, the student is able to draw on their own knowledge of the Civil Rights movement to pinpoint when the speech was most likely delivered.

Reflection was more prominent in the word cloud condition and most often occurred in the peer reply posts. For example, one student wrote to another, "Your post made me think about my own interpretation of the first speech and I realized that I probably misjudged the time period. You brought to my attention the words "sovereign" and "oligarchy," and also the fact that "African" is used as simply that, rather than African-American in the latter speech.” Reflection in the linear group was more often expressed on an individual level.

Finally, it appears that students in the linear condition had an edge in attributing tone to the speeches. In the examples in Table 3, for instance, the student in the linear condition goes as far as to characterize Anthony's speech as “docile.” An interesting contrast also appears in how students integrated the two speeches: the word cloud students tended to characterize the first word cloud (Susan B. Anthony's speech) as “angry,” whereas this word was more frequently used to describe the second speech in the linear condition.

\section{Co-Frequency of Codes}


While each of these codes indexed critical thinking, we were interested to see whether particular codes frequently appeared together. An analysis examining the co-frequency for every code was conducted for both conditions. The most noteworthy finding was that there were many more instances of the co-frequency of articulation of thought with citing evidence in the word cloud condition (43 times) than the linear condition (4 times). No other substantial co-frequencies were found in either condition.

The passage below illustrates the co-presence of articulation of thought and citing evidence in the word cloud condition:

The words "women" and "citizens" seem to be the focal point which makes me believe the main topic in the speech. Some other key words I noticed were "constitution", "right", and "vote." The speaker must have been pushing, or fighting for women citizens' right to vote. I think that the other important word to mention is "oligarchy." I believe that that along with the mention of the word "sex", which I believe to be referring to gender, may mean that the "government" is led by the dominant sex. As we have mentioned many times is class the dominant sex tends to be "male". Though I can't remember her name I feel positive in guessing that this speech may have been written by a feminist who wanted to push women's rights to vote.

In this passage, the student cites specific words (citing evidence) in the word cloud as s/he articulates her/his interpretation (articulation of thought). The student explains how s/he arrives at the conclusion that the speech was written by a suffragist. Although the student does not clearly propose a name, the reader can clearly see how s/he arrives at this conclusion. Hence, the post above is an example of how the word cloud condition may illustrate process.

The co-frequency of these codes in the linear condition is much lower. Moreover, these posts also appear rather different than those in the word cloud condition:

The first clue about the author is the statement that read, "It was we, the people; not we, the white male citizens; nor yet we, the male citizens; but we, the whole people, who formed the Union." This statement is crucial to understanding the frustration that the author, who is most likely a woman, as she directly addresses the problem of inequality between the two sexes in the United States.

The student above cites an entire sentence from the speech, and notes that the quoted statement is a "clue" about the author's identity. In contrast to the word cloud condition example, where the reader can see the student working through the words to come to a conclusion, this student's thought process seems complete. Rather than expressing a guess, the student is making an argument. Thus, this post more clearly illustrates the student's command of content over process. However, this interpretation should be tempered by the fact that the co-frequency of these two codes was dramatically lower in the linear condition than it was in the word cloud condition.

\section{Discussion}

Through analysis of code frequency and the content of the discussion posts, there are several implications about the integration of word clouds into online discussions pertaining critical thinking. While participants in both conditions were encouraged to think critically during the discussion, it appears that analyzing text in word cloud form prompts discussants to exhibit the 
thinking in a more visible manner. Importantly, participants in the word cloud condition exhibited a greater amount of critical thinking in general; a greater amount of indicators such as articulating thought, citing evidence, integration, and reflection; and more overlapping of different dimensions of critical thinking in the form of articulating thought processes and citing evidence. However, it should be stressed that the differences between the posts in both conditions point to the need to consider assignment objectives before implementing this teaching strategy. For example, the linear speech condition resulted in posts that predominantly rely on context and previous knowledge to build an argument, while the word cloud condition resulted in process-oriented, exploratory discussion posts that highlight the thinking process. Instructors must be mindful of these differences and consider what the overall learning objectives are for the discussion.

Looking more deeply at the actual discussion content, there appear to be certain conditions in which having word clouds is particularly advantageous. Our data suggests that the lack of linear text and context experienced through word clouds provides an environment that is more effective in prompting students to articulate their thought processes, cite evidence, integrate, and reflect in online discussions. As one student explained in the feedback survey, "Word clouds force you to look at specific words and derive meaning from those individual terms instead of just reading an entire sentence and taking it for what it is." Thus, the word cloud teaching strategy is more appropriate for use in process-centered assignments that have the development of critical thinking skills as a main objective. It is recommended to use word clouds when the instructor expects the student to show their active process of thinking, which can reveal their first impressions of content and what is relevant for them. Main ideas and themes can be explored without being too thrust into a complex context, such as a lengthy speech. In the survey, one student analyzing the word clouds expressed, "I felt this assignment was very valuable. I enjoyed the free-thinking that came with it.” In addition, exploration between peers may be richer when exploring word clouds. The free thinking nature encouraged students to speculate together, rather than simply agree or disagree.

Based on what was found in this exploratory study, analyzing text in a traditional linear fashion appears to be more appropriate if the overall discussion objective is content-centered. If the instructor's goal is to have students form well-reasoned arguments backed up by specific evidence (and relating previous knowledge), then the linear option may be more suitable. The use of linear texts may also be more appropriate for true reading comprehension. The linear condition also appears to capture the tone and emotion of a text more accurately than word clouds.

\section{Conclusion}

Supporting the development of students' critical thinking skills is a priority in higher education, and particularly challenging in online undergraduate environments. With the rise in online courses, mixed results have been found regarding critical thinking within online discussions. This exploratory study is significant in that it provides empirical evidence suggesting that analyzing text in word cloud form within online discussions is associated with higher levels of critical thinking in the online environment. In the study, the actual content of participants is analyzed to better understand the dimensions of critical thinking when faced with different text displays.

Research findings, student feedback, and trial-and-error over the course of several semesters have lead us to formulate recommendations to improve this and other assignments involving word clouds. First, it is important to explain what word clouds are. Some students reported difficulty with interpreting the word clouds at first. Particularly in blended settings, it may be advisable to analyze a word cloud together as a group before incorporating them into an 
assignment. By the same token, the analysis of word clouds should challenge students to think differently, so some difficulty should be expected. The location and placement of words is important and warrants some attention. If possible, certain words should be kept together in order to preserve certain phrases that are crucial for understanding.

Although these research findings are promising, this study faces certain limitations. The research is limited in scope and must be considered purely exploratory. The sample size is small and was limited to one course, one instructor, one institution, and one discussion assignment. Future research could include a larger sample size and other kinds of discussion assignments across two or more disciplines, professors, and institutions. Moreover, as described above, there are many ways to incorporate word clouds into online discussions beyond the single approach presented in this research. Future research should include assessment of other word cloud techniques. A promising research direction could be to examine the effectiveness of designing an assignment that pairs the two conditions. For instance, the word cloud can initially be used to explore ideas about the text, followed by an analysis of the text in its entirety. Students can then reflect on their perceptions about their first impressions, and be asked if their viewpoints have changed. It is important to note that this strategy could easily be applied to a face-to-face environment, with word clouds being projected on a screen and discussed as a group. It is recommended to research this direction as well to understand how analyzing word clouds in the moment differs from an asynchronous setting.

With the rise in online courses, students need to have multiple ways to develop and demonstrate critical thinking skills. Our study finds that word clouds emerge as one potential tool to accomplish this need.

\section{Appendices}

\section{Appendix 1. Discussion Assignment 5.}

We're doing something a little different for our final graded discussion of the semester! For this assignment, I selected two speeches written at different points in history written by two people involved in important social movements. I'd like you to:

Click on your group to view the speeches. They are contained in the first post.

- FOR WEDNESDAY: Analyze these speeches, and speculate about who might have written them, at what point in history, and with what purpose. Explain what particular words tipped you off, and why. Getting the author “right” isn't as important as analyzing the text for themes and meanings. Once you have analyzed the texts, compare them to each other and reflect on how the use of language might have changed over time.

- FOR FRIDAY: Once you submit your answer, go back to Module 8. Review the concept of performance as a display or verbal artistry and performativity (both in Austin's construction of language as action and Butler's work on gender and performativity). How might these theories inform your analysis of these texts? Take some time to give this some thought. Then, click on "reply" which is right underneath your first post, and reflect on how these theories can inform your interpretation of the text above (do not edit your first post).

- ALSO FOR FRIDAY: Next, pick someone in your group who has a different guess or a different interpretation, and respond to them. 
- $\quad$ FINALLY: Take the Discussion Survey to provide feedback about this activity

Do not Google the texts, it will ruin the fun! I will reveal who wrote what passage after the assignment has closed :).

\section{Appendix 2. Survey Questions (critical thinking items marked with *)}

5-point Likert scale: Agree-somewhat agree-neither agree nor disagree-somewhat disagreedisagree

1. The assignment instructions were clear. I understood what I was supposed to do.

2. I enjoyed doing this assignment.

3. I was more motivated to complete this assignment than other discussions.

4. I found this assignment: intriguing; exciting; both intriguing and exciting; neither intriguing nor exciting

5. I think this assignment is valuable.

6. *This assignment required me to use my critical thinking abilities.

7. *Not knowing the names of the authors of the speeches encouraged me to think about the speech in a more objective manner.

8. *This assignment challenged the way I think.

9. Having to guess the authors of the speeches made the discussion activity more engaging.

10. *This discussion activity encouraged me to think about the class content in a new way.

11. *This assignment encouraged me to write about how I think rather than what I think.

12. This discussion activity held my attention longer than other discussion activities.

13. This assignment promoted interactions with my classmates.

14. *Reading my peers' responses encouraged me to reflect on the way I thought about the discussion.

15. *This assignment encouraged me to think "outside of the box."

16. It took me an excessive amount of time to complete this assignment.

17. How much time did you spend on this assignment?

18. This assignment should be used in future classes.

19. Please use this space to give me any additional feedback about this assignment.

\section{References}

Allen, I.E., \& Seaman, J. (2014). Grade change: Tracking online education in the United States. Retrieved June 10, 2016 ,from http://www.onlinelearningsurvey.com/reports/gradechange.pdf

Arend, B. (2009). Encouraging critical thinking in online threaded discussions. Journal of Educators Online, 6 (1), n1.

Bandeen, H., \& Sawin, J. (2012). Encourage students to read through the use of data visualization. College Teaching, 60, 38-39. 
Baralt, M., Pennestri, S., \& Selvandin, M. (2011). Action research: Using wordles to teach foreign language writing. Language Learning \& Technology, 15 (2), 12-22.

Behar-Horenstein, L.S., \& Niu, L. (2011). Teaching critical thinking skills in higher education: A review of the literature. Journal of College Teaching \& Learning, 8 (2), 25-41.

Beyer, B.K. (1987). Practical strategies for the teaching of thinking. Boston, MA: Allyn and Bacon, Inc.

Bromley, K. (2013). Using word clouds in the classroom. The Utah Journal of Literacy, 16(1), 39-41.

Celentin, P. (2007). Online education: Analysis of interaction and knowledge building patterns among foreign language teachers. The Journal of Distance Education, 21 (3), 39-58.

DaPaolo, C.A., \& Wilkinson, K. (2014). Get your head into the clouds: Using word clouds for analyzing qualitative assessment data. Tech Trends, 58 (3), 38-44. doi:10.1007/s11528014-0750-9

Darabi, A., Arrastia, M.C., Nelson, D.W., Cornille, T., \& Liang, X. (2011). Cognitive presence in asynchronous online learning: A comparison of four discussion strategies. Journal of Computer Assisted Learning, 27 (3), 216-227. doi: 10.1111/j.1365-2729.2010.00392.x

deNoyelles, A., \& Reyes-Foster, B. (2015). Using word clouds in online discussions to support critical thinking and engagement. Online Learning Journal, 19(4), 1-12.

Edyburn, D. (2010). Word clouds: Valuable tools when you can't see ideas through the words. Journal of Special Education Technology, 25 (2), 68-72.

Facione, P. (1990). Critical thinking: A statement of expert consensus for purposes of educational assessment and instruction. Millbrae, CA: The California Academic Press.

Garrison, D.R. (2007). Online community of inquiry review: Social, cognitive, and teaching presence issues. Journal of Asynchronous Learning Networks, 11 (1), 61-72.

Gerber, S., Scott, L., Clements, D.H., \& Sarama, J. (2005). Instructor influence on reasoned argument in discussion boards. Educational Technology Research and Development, 53 (2), 2539.

Hamm, S.E. (2011). Using word clouds for reflection and discussion in an online class. Teaching Theology and Religion, 14 (2), 156.

Hayes, S. (2008). Toolkit: Wordle. Voices from the Middle, 16 (2), 66-68.

Huisman R., Miller, W., \& Trinoskey, J. (2011, October). We’ve Wordled, have you? Digital images in the library classroom. College \&Research Libraries News. 
Joyner, F. (2012). Increasing student interaction and the development of critical thinking in asynchronous threaded discussions. Journal of Teaching and Learning with Technology, 1 (1), 3541.

Kanuka, H., Rourke, L., \& Laflamme, E. (2007). The influence of instructional methods on the quality of online discussion. British Journal of Educational Technology, 38 (2), 260-271.

Kaptein, R., Hiemstra, D., \& Kamps, J. (2010). How different are language models and word clouds? In 32nd European Conference on Information Retrieval (ECIR 2010) (pp. 556-568). Retrieved from June 10, 2016, http://link.springer.com/chapter/10.1007\%2F978-3-642-12275$\underline{0 \_48}$

Lai, E.R. (2011). Critical thinking: A literature review. Pearson’s Assessments. Retrieved June 10, 2016, from http://www.pearsonassessments.com/hai/images/tmrs/criticalthinkingreviewfinal.pdf

Lynch, D. J., Kearsley, G., \& Thompson, K. (2011). Faculty use of asynchronous discussions in online learning. International Journal of Instructional Technology and Distance Learning, 8 (2), 17-24. Retrieved June 10, 2016, from http://www.itdl.org/Journal/Feb_11/article02.htm

Miley, F., \& Read, A. (2012). Using word clouds to develop proactive learners. Journal of the Scholarship of Teaching and Learning, 11 (2), 91-110.

Nickel, J. (2012). Word clouds in math classrooms. Mathematics Teaching in the Middle School, 17 (9), 565-566.

Nussbaum, E.M., Winsor, D.L., Aqui, Y.M., \& Poliquin, A.M. (2007). Putting the pieces together: Online argumentation vee diagrams enhance thinking during discussions. ComputerSupported Collaborative Learning, 2, 479-500.

Paul, R.W., \& Elder, L. (2000). Critical thinking: Basic theory and instructional structures handbook. Foundation for Critical Thinking.

Perry, L. (2012). Using word clouds to teach about speaking style. Communication Teacher, 26 (4), 220-226.

Ramsden, A., \& Bate, A. (2008). Using word clouds in teaching and learning. Retrieved June 10, 2016, from http://opus.bath.ac.uk/474/

Richardson, J.C., \& Ice, P. (2010). Investigating students’ level of critical thinking across instructional strategies in online discussions. The Internet and Higher Education, 13 (1), 52-59.

Simpson E., \& Courtney, M. (2002). Critical thinking in nursing education: literature review International Journal of Nursing Practice, 8, 89-98. 
Reyes-Foster and deNoyelles

Stedman, N.L.P., \& Adams, B.L. (2014). Getting it to click: Students self-perceived critical thinking style and perceptions of critical thinking instruction in face-to-face and online course delivery. NACTA Journal, 58 (3), 236-243.

Yang, Y., Newby, T., \& Bill, R. (2005). Using Socratic questioning to promote critical thinking skills through asynchronous discussion forums in distance learning environments. The American Journal of Distance Education, 19 (3), 163-181. 